\title{
$\begin{array}{ll}\text { Research Square } & \text { Preprints are preliminary reports that have not undergone peer review. }\end{array}$ or referenced by the media as validated information. \\ Bibliometric study of the combustion of cane cutting waste (RAC) in the capture of Carbon Dioxide.
}

SANDRA EMPERATRIZ PEÑA ( $\square$ sandra.penam@ug.edu.ec )

Universidad de Guayaquil https://orcid.org/0000-0002-7848-8021

\section{CARMEN FORERO}

Univalle: Universidad del Valle

FRANCISCO VELASCO

Universidad del Valle

\section{Research Article}

Keywords: chemical looping combustión, capture, carbon dioxide, biomass, energy

Posted Date: December 2nd, 2021

DOI: https://doi.org/10.21203/rs.3.rs-1061427/v1

License: (c) (i) This work is licensed under a Creative Commons Attribution 4.0 International License.

Read Full License 


\section{Abstract}

Objective: To describe the combustion process of sugarcane RAC with $\mathrm{CO}_{2}$ capture by manganese-based oxygen transporters during the period 2015-2021.

Design: Bibliometric observational study. Location: Combustion of cutting waste with $\mathrm{CO}_{2}$ capture by manganese-based oxygen conveyors.

Main measures: Magazine, year of publication, first/last author, workplace and autonomous community were obtained in each register. Subsequently, the articles were classified according to their content or research area. The impact factor was obtained from the bibliometric analysis base of Scopus and Vos viewer.

Results: Through the search criteria used, 475 documents were recovered in the 2015-2021 semester, excluding 2637 because they did not correspond to affiliation to centers or institutions directly related to documents related to chemical combustion and $\mathrm{CO}_{2}$ capture. In total, 73 documents were selected, in which an increase and interest in the study of these processes was verified both in the research areas and in the journals in which they are published. Most of the studies have been published in universities or research centers and differences were observed in terms of the volume of international and national scientific production, so it is necessary to increase these investigations in the country of Colombia.

\section{Highlights}

- Cane cutting waste has high potential as a fuel in the generation of electrical energy.

- Thermochemical processes with a carbonaceous substrate, it is transformed into a combustible gas of calorific value.

- The oxidation and reduction reactions generated in CLC produce carbon monoxide, carbon dioxide, solid waste.

- Biomass in gasification is a carbonaceous fuel with useful energy.

\section{Introduction}

Lignocellulosic biomass is a major source of renewable energy with potential in the production of biofuels with NEUTRAL $\mathrm{CO}_{2}$ emissions, cogeneration of electrical energy and generation of compounds [1]. Itis so named because ofits chemical composition which structurally possesses: cellulose, hemicellulose and lignin and in smaller quantities starch polysaccharides, proteins, and other watersoluble organic substances [2]. Among the biomass, there are the agricultural residues that are obtained from the sugarcane harvest and these are: straw, stems pods and dried leaves, is what is called as RAC (Cutting Residues)[1] 
The RACS are used as a source of animal feed, or raw material of several processes, the present work focuses on the fact that they have a high potential as a fuel in the generation of electrical energy based on being a renewable resource with high availability, presenting good properties as fuel and effective technology for its use. According to what León-Martínez (2013) said, it is estimated that the RACs correspond to 15 to $20 \%$ in relation to the weight of the cane, with humidity of $15 \%$, which responds to its high volume and the large amount of energy that can be [1] used.

All scientific publications and the results of research on biomass are shared by the scientific community, so it is contributed to the advancement of knowledge, the publication is an essential phase of this, so it is also known about the combustion by oxygen transporters of the same stands out as one of the most promising $\mathrm{CO}_{2}$ capture technologies thanks to the low energy penalty due to the separation of $\mathrm{CO}_{2}$, andits consequent low cost. [3] These disseminations of new knowledge make a decisive contribution to scientific progress.

The analysis of the publications in this CLC area has made it possible and to value the scientific productivity, since the bibliometric indicates have the advantage of being objective and serve to compose the judgment of the experts. [2] However, despite its used and its unquestionable value, it is necessary to analyze bibliographic citations that have limitations when used as the only mechanism for evaluating scientific activity. For the IPCC (2019), in publications production and use of biomass for bioenergy may have benefits, adverse side effects and risks to land degradation, food insecurity, GHG emissions and other environmental and sustainable development objectives; so that in journals with high factor of bibliographic impact, relevant information is obtained in knowledge about the advances of biotechnology and agricultural industry. [4] Consequently, gases in the atmosphere that absorb infrared radiation from Earth or outgoing radiation are known as Greenhouse Gases (GHGs), including carbon dioxide, water vapor, nitrous oxide, methane, and ozone. These gases have molecules whose vibrational frequency is located in the infrared part of the spectrum. [5]

The Intergovernmental Panel on Climate Change displays three Working Groups and a Task Force each provide scientific, technical and socio-economic advice or, with global emphasis, in particular to the countries that are members of the United Nations Framework Convention on Climate Change(UNFCCC). [6]

There are mutually supportive climate and land policies that can save resources, increase social resilience, support ecological restoration, and foster multi-stakeholder engagement and collaboration[4]

The Energy Plan for 2050 in Colombia mentions in these objectives, promoting the efficient management of energy demand and incorporating clean transport technologies. With this objective, it seeks to reduce the energy intensity of the country, thus contributing to low-carbon development, by achieving a decrease in demand and efficiency in consumption. [7]

It is already possible in the country to increase the bibliometric culture, its evolution and extraordinaire is evidenced; there are several studies on the $\mathrm{CLC}, \mathrm{CO}_{2}$ capture, and a whole energy plan for 2050 at the 
country level. Some studies already show the specific concepts of thermochemical friction in which a carbonaceous substrate (organic matter) is transformed into a combustible gas of low or medium calorific value by a gasifying agent under certain operating conditions. [8] Other studies describe international scientific production, specifying positive aspects of the use of organic industrial waste, whether solid or liquid, stimulating the continuous desire for research. [8]

On the other hand, although scientific publications on technological advances in $\mathrm{CLC}$ and $\mathrm{CO}_{2}$ capture in Colombia focus on the use of organic waste to reduce environmental impact, there is also the scientific production of journals of numerous specialties, indicating that in low-cost materials based on iron and manganese, with potential as TSO in CLC technology. [9]

Although there is progress of several investigations, there is still a lack of bibliometric studies on the combustion processes from the residue of cutting and bagasse of sugar cane, they provide very useful information about the professional activity and research carried out. [10]

Analyzing others, such as the volume of research activity, its evolution in time, the type of research, the topics addressed, the groups and centers most active in the different areas and the collaborations between them. Reason why, the objective of this research was to determine the scientific production of $\mathrm{CLC}$ and $\mathrm{CO}_{2}$ capture with the residues of cutting and bagasse of sugar cane, analyzing its geographical distribution, the impact factor of the journals involved, the main areas of research and the participation of the different institutional sectors.

\section{Methods}

The present study is an observational study of bibliographical character and international scope where the time frame has been the period 2015-2021. The study units were the scientific articles directly related to the processes of $\mathrm{CLC}$ in the capture of $\mathrm{CO}_{2}$, with racs and bagasse of sugar cane, published in any scientific journal of a period indexed in the Scopus database, carrying out a generic search strategy to recover the largest possible number of references published in each autonomous community during the study period.

The following search criteria were used for this purpose: 'chemical looping combustion', 'carbon dioxide capture', 'manganese-based 'and 'oxygen carrier'.

Then each of the documents recovered was manually reviewed, excluding those that did not correspond to the $\mathrm{CLC}$ and $\mathrm{CO}_{2}$ capture, based on the information contained in the title, abstract and affiliation data.

In each of the records obtained, the following variable quantity were collected: title of the journal, year of publication, surnames and initials of the first and last author, institution or place of work of the signatory primer and autonomous community. 
Subsequently the articles were basified the following sources; Energy and fuels, Applied energy, biofuel, International Yearbook of Green Energy and Gas, Yearbook of Chemical Engineering, Biotechnology for Biofuels, Energy and Energy Technology, Research in Industrial and Engineering Chemistry.

In cases where more than one institution was mentioned, the item was assigned to the one in the first place and documents that have few research matches were rejected, as illustrated in Figure 1.

By means of the criteria of use, 475 papers were recovered in the six-year period 2015-2021, excluding 2162 because their affiliation did not correspond to centers institutions directly related to documents related to the $\mathrm{CLC}$ and $\mathrm{CO}_{2}$ capture. In total, 212 documents were selected, and 10 different authors were identified as shown in Figure 2.

In Figure 3, the various percentages of the analysis of the documents by area of study are indicated, in Energy 125 journals were found (25.5\%), in Chemical Engineering 107 journals were found $(21,8 \%)$, in Environmental Science 81 (16,5\%), In Chemistry 74 (15,1\%), in Engineering 71 (14.5\%), Physics and Astronomy 12 (2,4\%), in Materials Sciences 10 (2.0\%), in Biochemistry, Genetics and Molecular Biology 5 (1.0\%), Agricultural and Biological Sciences $2(0,4 \%)$, and in other documents $4(0,6 \%)$.

When analyzing the documents by year, between the period of 2015 and 2021 the first five years there were more publications, being in the 2015 and 2020 where they disseminated 40 and 44 articles respectively reaching the highest points. In the year 2019 there is a decrease in the number of publications to 26, but without minimizing its importance, that even by 2021 there are already 9 articles related to the processes of $\mathrm{CLC}$ and $\mathrm{CO}_{2}$ capture (Figure 4).

We identified 23 studies related to Energy and Fuels between 2015 and 2020, being the maximum relevant investigate source, while in the area of Chemical, Industrial and Engineering Research, only 6 sources were found, as shown in Figure 5.

When searching the documents according to affiliation it was determined that in the country of China is where a greater number of publications have been published finding 71 investigations being the Chalmer University of Technology of China where they have carried out the largest number of studies. In the case of South America, 3 scientific journals disseminated in the country of Brazil were identified, being in the Institute of Energy and Fuels where they have studied in greater depth, determining that studies related to the process of manganese transporters is little investigated (Figure 6). Considering that the country of China has the largest number of studies, the most relevant authors are Abad, A; Linfelt, A and Adanez, J, as shown in Figure 7. To complement this analysis, it was determined that China, the United States and Spain are the countries where this study has the greatest relevance while in Iran there are only 7 publications during the period 2015 and 2021 (Figure 8).

Finally, we investigated the types of research carried out during the period of this bibliometric study, finding 170 articles $(80.2 \%), 24$ reviews (11.3\%), 10 documents of book chapters $(4,7 \%)$, conference articles $7(3,3 \%)$ and 1 retracted $(0,5 \%)$ as shown in Figure 9. 
In the following active map of the $\mathrm{CLC}$ process, $\mathrm{CO}_{2}$ capture, with rac biomass from sugarcane. At the national and international level, it was detected, from the correlation when using the carbon dioxide word in most cases, the grouping when publishing of several authors. The green dot carbon dioxide), the largest, is in relation to each author publishing a large number of articles. Twenty-four articles have been considered in this study that, in addition, is not closed, marked on the active map with a different color (Figure 10). For a greater understanding of the identification of the networks academics, has proceeded to establish the results through Vos's viewer identify the groupings or cluster.

One of the most widely used methods for $\mathrm{CO}_{2}$ capture developments with sugarcane races has been chemical reactors, CLC (Figure 11). To indirect combustion with solid oxygen transporters (Chemical Looping Combustion - $\mathrm{CLC}$ ), is an energy efficient alternative for capturing $\mathrm{CO}_{2}$, as it is a technology with inherent separation of $\mathrm{CO}_{2}$ through the use of solid oxygen conveyors - TOs (metal oxides). [11]

Whereas CLC technology uses oxygen transporters, which are basically metal oxides of copper, nickel, manganese, iron or cobalt, based on an inert species acting as a porous matrix, gives surface area and mechanical resistance to the transporter in the capture of $\mathrm{CO}_{2}$, figure 12 illustrates that this process and is broadly related to this reaction[12].

\section{Results}

Through the search criteria used, 475 documents were recovered in the 2015-2021 semester, excluding 2637 because they did not correspond to affiliation to centers or institutions directly related to documents related to chemical combustion and $\mathrm{CO}_{2}$ capture. In total, 73 documents were selected, in which an increase and interest in the study of these processes was verified both in the research areas and in the journals in which they are published. Most of the studies have been published in universities or research centers and differences were observed in terms of the volume of international and national scientific production, so it is necessary to increase these investigations in the country of Colombia.

\section{Discussions}

In the recent scientific production indexed in Scopus related to the process of Chemical Looping Combustion in the capture of $\mathrm{CO}_{2}$, with solid oxygen transporters, a wide diversity of documents was observed, both by the research areas and by the journals where they are published, proving that the main authors, have published between 9 and 14 articles in the last 5 years, on average them majority of authors have published two years during the last 5 years. The increase in production has been progressive in this period, and most of the work has originated in universities or research institutes with an increasing trending recent year. Despite the difficulty in classifying the content of the articles, it is verified, as it happens in previous studies, a predementias biotechnological studies, especially in the area of Chemical looping combustion for the capture of $\mathrm{CO}_{2}$. 
In the case of the most frequented journals associated to the subject of study, the number of researches has increased during the last five years, a long way from the other years. Altogether, most studies have been conducted in the Eastern continent specifically in the country of China, the country of the United States is the main exponent dedicated to the process of CLC in the capture of $\mathrm{CO}_{2}$, using oxygen transporters, followed by Spain and Switzerland. In addition, the superiority of publications when they have been produced in research units or institutes was observed, as well as their bibliographic impact factor. Some autonomous communities stand out for a greater number of documents in relation to the number of inhabitants, and in them there is also a higher proportion of articles published in journals in other countries.

Although the scientific output of the CLC process in $\mathrm{CO}_{2}$ capture, its relevance and impact have not reached the desired level in the whole of biotechnological research in recent years, research in this field and the desire of several countries to improve $\mathrm{CO} 2$ levels in the environment, are recognized in the Intergovernmental Group of the United Nations, where: Five members of the G20 (the European Union and four countries) have signed up to the obligation to reduce their emissions to zero in the long term; three of them are hip the process of adopting laws in this regard and the other two have recently done so. The remaining 15 members have not yet made this commitment at the international level. [13] In general terms, the processes of capturing $\mathrm{CO}_{2}$ by CLC in Colombia is still an emerging discipline when compared to other countries such as China, the United States or Spain, where research is more consolidated.

Bibliographically the gasification process is a method used to obtain a gaseous fuel, carbon monoxide mostly and to a lesser extent hydrogen, from another fuel, such as any type of biomass with carbon content,[14] although once the process is started, another series of components that accompany said carbon monoxide in a more or less proportion is obtained, such as carbon dioxide, solid waste and other components resulting from the reactions that occur parallel to the gasification. These include pyrolysis, oxidation, and even hydrogenation. [15]

The development of gasification technology makes it possible to recover the energy present in waste materials, such as biomass. Within the energy use of biomass, gasification consists of the conversion by partial oxidation at high temperature of a carbonaceous fuel into a gas with useful energy. [16]

At the moment in Colombia it recognizes the need to promote development or research into these operations and the lack of viability of scientific production has been highlighted. [16]

The increase in recent years and the higher impact fact from specific study structures observed in the results indicate that more resources are needed and the consolidation of such structures (research units, networks and CLC study institutes). The results also indicated a high rate of transitory in the research, which suggests implementing strategies for consolidating line and research sets. It is possible that the creation of university departments of Biotechnology, as has happened in almost all Western countries, can also serve as a strategy to improve the volume and quality of research. In order to see if this happens 
in the coming years and to be able to quantify the magnitude of the changes, bibliometric studies will continue to be of the utmost use.

\section{Conclusions}

In conclusion, in the published documents related to the methods of CLC with solid oxygen transporters, in recent years at the international level there was an increase or interest in the study of these methods and reactions both in the research areas and cutting-edge the journals in which they are published. Most studies have been published in universities or research centers and differences were observed in terms of the volume of international and national scientific production, being necessary to increase these investigations in the country of Colombia

- Scientific publications allow the dissemination of new knowledge and make a decisive contribution to scientific progress.

- The bibliometric studies related to the methods of $\mathrm{CLC}$ in the capture of $\mathrm{CO}_{2}$, provide useful information on the professional activity and the research developed, analyzing, among others, aspects such as the volume of scientific production and its temporal evolution.

- The publications arising from the subject studied are distributed in journals of numerous specialties, which, together with the lack of updating of bibliometric studies, makes it difficult to evaluate scientific production.

- The increase in the scientific production of the chemical looping combustion process in the capture of $\mathrm{CO}_{2}$, which has been progressive over the last few years. The publications were dominated by biotechnological studies in the area of energy and fuels from organic waste.

- Some autonomous communities stand out for a greater number of documents in relation to the number of inhabitants, in which there is also a higher proportion of articles published in journals in other countries.

\section{Abbreviations}

CLC

Chemical looping combustion

$\mathrm{CO}_{2}$

Carbon Dioxide

G20

the European Union and four countries

GHG

Greenhouse Gases

IPPC

Intergovernmental Panel on Climate

UNFCCC 
United Nations Framework Convention on Climate Change

RAC

Cutting Residues of sugar cane

Scopus

is a bibliographic database containing abstracts and citations for academic journal articles

TSO

Oxygen transporter

Vos viewer

is a software tool to build and visualize bibliometric

\section{Declarations}

\section{Declarations}

Not applicable

\section{Availability of data and material}

E-mails: Sandra Peña Murillo: sandra.penam@ug.edu.ec; Carmen

Forero: carmen.forero@correounivalle.edu.co; Francisco

Velasco francisco.velasco@correounivalle.edu.co

all references are available at mendeley

\section{Competing interests}

The authors declare that they have no conflict of interest.

\section{Funding}

Not applicable

\section{Authors' contributions}

All authors have read and approved the manuscript

SP: author, design of the work

CF: Responsible for the results and conclusions, have drafted the work or substantively revised it

FV: in charge of reviewing the included methodology and the document

\section{Acknowledgements}


I am grateful to the University of Guayaquil, since it has collaborated with the respective permits with payment of my salaries, which has allowed me to sustain my postgraduate academic values.

Infinite thanks to the Gas and Combustion Laboratory Group of the Universidad del Valle, Cali-Colombia, for the knowledge transmitted to the professors and the facilities for this doctoral study.

\section{References}

[1] Peña M, Sandra E.; López,J "Desarrollo sostenible y oportunidad de aprendizaje de las biorrefinerías: Una alternativa de la biomass/ Desarrollo sostenible y oportunidad de aprendizaje de las biorrefinerías: Una alternativa de biomass", Rev. Ciencias Soc., vol. XXVI, 2020, doi: 10.31876/rcs.v26i0.34135.

[2] Y. A. VARGAS CORREDOR and L. I. PEREZ PEREZ, "APROVECHAMIENTO DE RESIDUOS AGROINDUSTRIALES EN EL MEJORA DE LA CALIDAD DEL AMBIENTE," Rev. Fac. Basic Sciences, vol. 14, no. 1, pp. 1-14, 2018, [Online]. Available:

http://revistas.unimilitar.edu.co/index.php/rfcb/issue/view/245/80.

[3] P. Anton, "DOCTORAL THESIS CHEMICAL LOOPING COMBUSTION OF BIOMASS WITH NEGATIVE CO 2 EMISSIONS," 2019.

[4] IPCC, Climate Change and the Earth. 2019.

[5] H. O. Benavides, "Información técnica sobre Gases de Efecto Invernadero y el cambio climático.," Ideam, pp. 1-102, 2007, doi: IDEAM-METEO/008-2007.

[6] U. Nations, "'The warming of the climate system is unequivocal':Highlights of the Fourth Assessment Report of the Intergovernmental Panel on Climate Change | United Nations." [Online]. Available: https://www.un.org/es/chronicle/article/el-calentamiento-del-sistema-climatico-es-inequivocoaspectosmas-destacados-del-cuarto-informe-de.

[7] UPME, "Plan Energética Nacional Colombia: Ideario Energética 2050," Unidad Planeación Min. Energética, Repub. Colomb. , p. 184, 2015, [Online]. Available: http://www.upme.gov.co/Docs/PEN/PEN_IdearioEnergetico2050.pdf.

[8] L. Monge, "Biomass gasification as an energy source."

[9] E. Arango, "DEVELOPMENT OF LOW-COST SOLID OXYGEN CONVEYORS BASED ON IRON AND/OR MANGANESE AVAILABLE IN COLOMBIA USING CO AND H2 AS FUELS IN CLC (CHEMICAL LOOPING COMBUSTION) TECHNOLOGY.," 2013.

[10] S. L. J. Peña, "Estudio bibliométrico de la obtención de furfurales y hidroximetil furfurales a partir de bagosa de caña de azúcar." 
[11] C. R. Forero, "Combustion of gas with CO2 capture by solid oxygen transporters based on CuO.," Thesis Dr. , p. 152, 2011, [Online]. Available: http://digital.csic.es/bitstream/10261/34877/3/(ICB)Thesis Carmen Rosa Forero 2011.pdf.

[12] V. Tangarife, J. Maya, F. Chejne and E. Pabón, "Preparation and characterization of solid oxygen transporters based on copper", Rev. Colomb. Mater. , no. 5, pp. 27-34, 2013.

[13] United Nations Environment Programme, "Report on the 2019 Emissions Gap", Nac. United for the Ambient Environment. , p. 16, 2019, [Online]. Available: http://www.unenvironment.org/emissionsgap.

[14] J. Peña M, Sandra E.; Lusuriaga, Nathaly P.; Sanchez, Maria; López, "Furfural evaluation of pretreatments in three varieties of biomass", no. December 2020, 2021.

[15] U. de Sevilla, "Planta piloto de Gasificación de Biomasa," pp. 15-29, 2003.

[16] J.M. Mendoza Fandiño, "Estudio y caracterización teórico-experimental del proceso de gasificación de biomasa residual con adición de vapor",2015, [Online]. Available:

http://manglar.uninorte.edu.co/handle/10584/8167.

\section{Figures}

Scopus virtual platform database

Selection by means of bibliographic search criteria, of documents for obtaining furfural and hydroxyfurfural from sugar cane

Selected documents: 475 . Documents automatically excluded: 2637 . Documents automatically analyzed: 212

Descriptive a nalys is, geographic distribution and calculation of bibliometric indices

\section{Figure 1}

Outline of the study results (Source: by Autor)

\section{Figure 2}


Documents by author (Source: www.scopus.com)

Documents by subject area

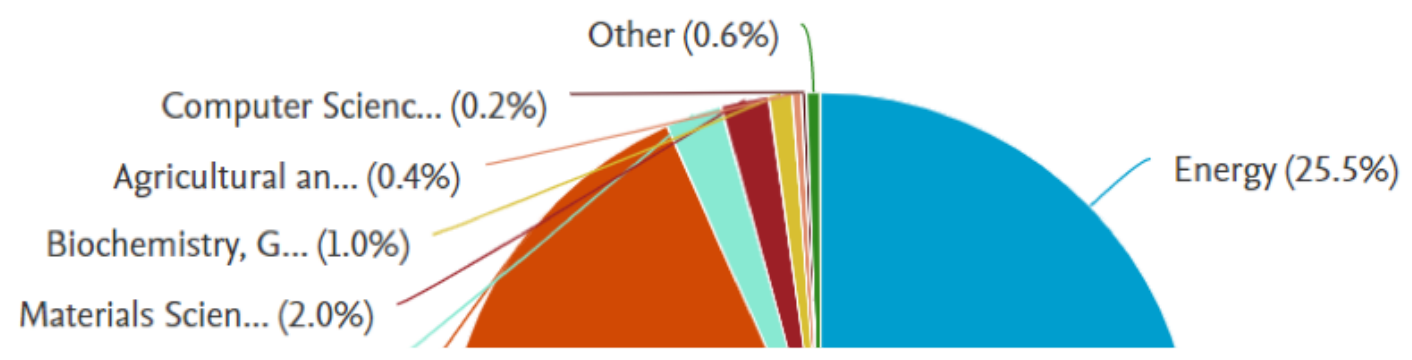

Figure 3

Documents by Area of Study (Source: www.scopus.com) 


\section{Documents by year}

50

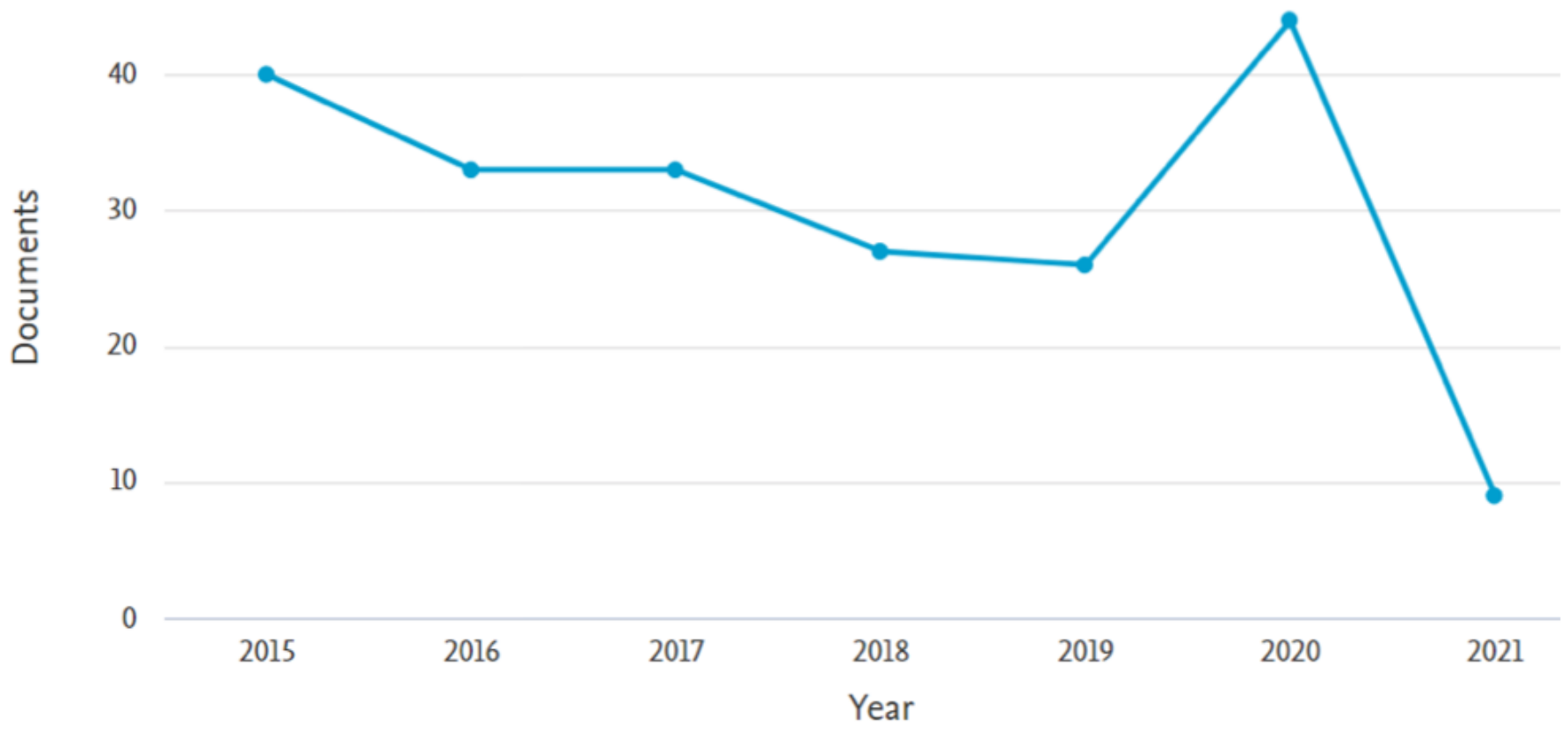

Figure 4

Documents by Year of publication (Source: www.scopus.com)

Documents per year by source

Compare the document counts for up to 10 sources.

Compare sources and view CiteScore, SJR, and SNIP d

10

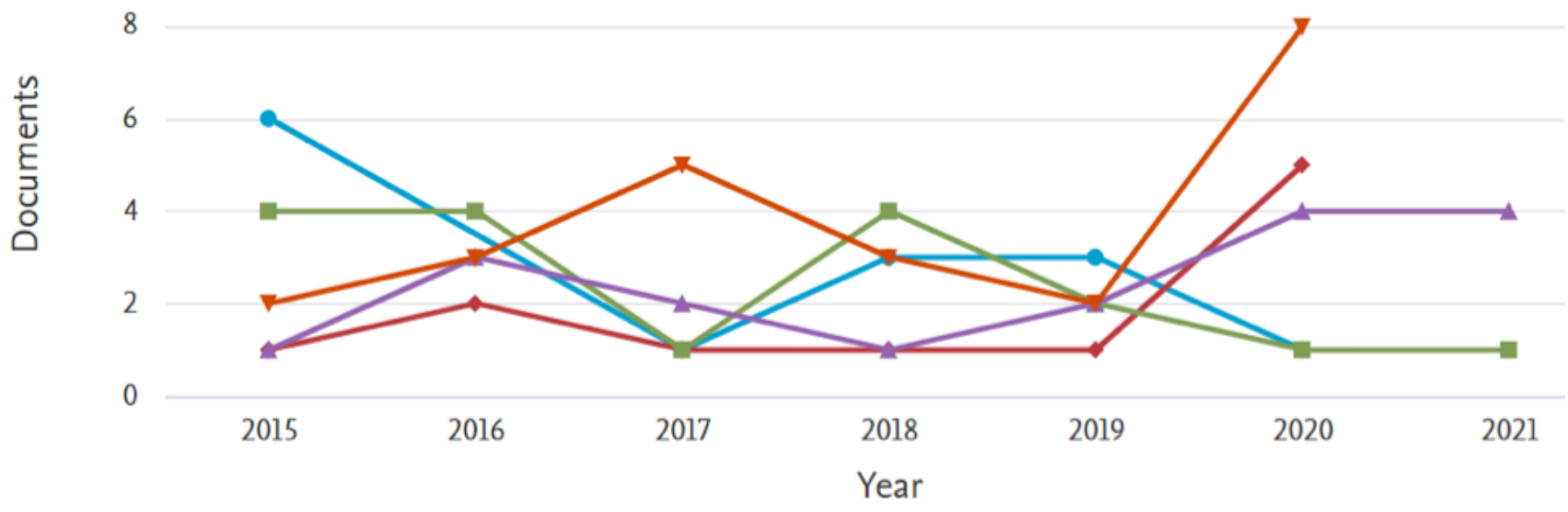

$\sim$ International Journal Of Greenhouse Gas Control $\leftrightarrow$ Chemical Engineering Journal $\quad-$ Applied Energy $\quad$ Fuel - Energy And Fuels

\section{Figure 5}


Documents by Year and by Source (Source: www.scopus.com)

\section{Figure 6}

Documents by Affiliation (Source: www.scopus.com)

\section{Figure 7}

Documents by Autor (Source: www.scopus.com)

\section{Figure 8}

Documents by Country or Territory (Source: www.scopus.com)

\section{Figure 9}

Documents by Type (Source: www.scopus.com)

\section{Figure 10}

Bibliometric map (Carbon dioxide) (Source: www.scopus.com)

\section{Figure 11}

Bibliometric map (CLC) (Source: www.vosviewer.com)

\section{Figure 12}

Bibliometric map (Oxygen transporter) (Source: www.vosviewer.com) 